\title{
Drug-induced sleep endoscopy (DISE) as a guide towards upper airway behavior and treatment outcome: the quest for a vigorous standardization of DISE
}

\author{
Olivier M. Vanderveken ${ }^{1,2}$ (D) \\ Received: 8 October 2018 / Accepted: 9 October 2018 / Published online: 18 October 2018 \\ (C) Springer Nature Switzerland AG 2018
}

Since its first description in 1991 [1], drug-induced sleep endoscopy or DISE has been progressively advocated as a useful assessment for patients with sleep-disordered breathing. A particular role for DISE has been to help determine the most suitable treatment option for the individual patient seeking an alternative for positive airway pressure (PAP) therapy [2]. With the increased use of DISE in both clinical practice and research projects, the need for standardization of the technique has become collectively recognized [3]. The need for standardization includes technical equipment and staffing, patient positioning and diagnostic maneuvers during DISE, drug usage, observation window, target events, and scoring and classification systems for DISE. These considerations have resulted in the publication of the "European position paper on DISE" in 2014 [4], with an update that was recently published [5]. This issue of the journal Sleep and Breathing contains up to seven manuscripts that all address different aspects regarding DISE and its standardization in one of these perspectives.

Vonk et al. provide an assessment of DISE as a selection tool for oral appliance therapy (OAT) and positional therapy in obstructive sleep apnea (OSA). The investigators evaluated the effect of different passive maneuvers such as manually performed jaw thrust and lateral head rotation on upper airway (UA) patency during DISE in two-hundred patients with OSA [6]. The analysis of the results revealed that overall the effect of jaw thrust on UA patency during DISE was more pronounced and that the effect of isolated lateral head rotation

Olivier M. Vanderveken

Olivier@ ovanderveken.be

1 Faculty of Medicine and Health Sciences, University of Antwerp, Antwerpen, Belgium

2 Department of ENT, Head and Neck Surgery, Antwerp University Hospital UZA, Wilrijkstraat 10, B-2650 Edegem, Belgium maneuver was smaller. In another paper from the same group, Beelen et al. [7] were able to further evaluate the influence of these two maneuvers on UA collapse levels and patterns during DISE. In this same patient cohort, it was shown that the combination of both maneuvers resulted in the most pronounced increase in UA re-opening at all collapse levels within the UA. On the other hand, the authors noted that jaw thrust led to a significant decrease in collapsibility at all collapse levels whereas with lateral head rotation alone an increase in obstruction was observed at the oropharyngeal level. At the other levels of UA collapse, there were significant improvements in terms of UA opening with this isolated lateral head rotation maneuver [7].

Currently, midazolam and propofol are the most widely used drugs for DISE, either to be used as a single agent or in combination [4]. Alternatively, a combination of these medicines with other drugs such as remifentanil or ketamine has been described [5]. In this issue of the journal, Kim et al. report on a placebo-controlled comparison of the effect of remifentanil on propofol concentrations during DISE [8]. Interestingly, the results of this study suggest that the additional use of remifentanil, a short-acting synthetic opioid analgesic drug, together with propofol significantly reduces the target concentration of propofol to about $0.5 \mu \mathrm{g} / \mathrm{ml}$ on average without respiratory depression. Moreover, the authors state that the time needed for sufficient sedation to be reached was significantly shorter, with a mean difference of about three minutes, in the remifentanil-propofol group compared to patients receiving propofol only [8]. The findings of this trial are relevant and the future research agenda should include further comparison of this regime with other combinations of drugs for DISE with a simultaneous attempt for further standardization of the drug regimen to be used [5].

The main indication to schedule a patient for DISE in routine clinical practice is to facilitate a decision toward PAP alternatives, such as upper airway surgery (including palatal 
surgery, tongue base surgery, and hypoglossal nerve stimulation), oral appliance therapy (OAT), positional therapy (PT), or a combined approach including different treatment modalities [2, 4, 5, 9-11]. Evidence in the literature indeed suggests that the pre-operative findings during DISE relate to the final surgical outcome and that awake assessment of the UA does not accurately correlate with the exploration of the UA during DISE [12-14]. In this issue of Sleep and Breathing, additional evidence on the added value of DISE towards UA surgery for adult patients with OSA is provided in the paper by Wang et al. [15]. In their retrospective study including eight-five patients with moderate to severe OSA who underwent tonsillectomy and/or uvulopalatopharyngoplasty (UPPP) the nonresponders were more likely to be diagnosed with a complete circular collapse at the level of the palate (CCCp) and/or a complete tongue base collapse during DISE. The responders, on the other hand, were more likely to have a partially anteroposterior palatal collapse as documented during their pre-operative DISE. These results, again, provide evidence that DISE has the clear potential to guide surgical treatment decision making in patients with OSA [15].

The specific DISE-phenotype of complete concentric collapse at the velopharynx or palate, referred to as CCCp, has been defined as an exclusion criterion for upper airway stimulation (UAS) therapy, using electrical neurostimulation of the hypoglossal nerve synchronized with ventilation $[11,16,17]$. In their paper, Hasselbacher et al. [18] were able to explore whether UPPP with tonsillectomy (UPPP-TE) would be able to remove the CCCp DISE-phenotype in fifteen patients with CPAP intolerance in order for these patients to fulfill the inclusion criteria for UAS after UPPP-TE. Before the treatment with UPPP-TE all patients presented with the CCCp phenotype during pre-operative DISE, while after UPPP-TE only one patient still exhibited CCCp during DISE. As a result, a large majority of these CPAP-intolerant patients would fulfill the criteria to be included in the UAS clinical program after UPPP-TE. These results are highly relevant for the field and highlight the role of DISE in a tailored approach to each individual patient with OSA [18].

Kastoer et al. report on a comparison of patients' characteristics in terms of UA collapse patterns in a large series of patients with and without OSA undergoing DISE with a special focus on positional OSA or POSA [19]. The presence of collapse at the level of the palate and/or the level of the oropharynx was found to increase the likelihood of POSA, while CCCp was found significantly more in non-POSA patients. In addition, while no differences were described in terms of OAT outcome, a lower efficacy of UA surgery was observed in patients with POSA compared to non-POSA. The latter finding again confirms the potential benefit of positional therapy in these patients in order to treat their residual POSA after UA surgery [20].

Finally, an interesting paper by Lan et al. reports on the evaluation of DISE for the prediction of CPAP titration in patients with OSA [21]. Patients with CCCp or a lateral oropharyngeal collapse during DISE required significantly higher CPAP pressure as determined during a CPAP titration polysomnography. The authors state that DISE findings could provide better understanding of the need for higher CPAP pressure settings in subgroups of patients with OSA. At the same time, DISE can be a tool to identify the indications for OAT or surgery in order to lower titrated CPAP levels and thereby improve adherence and compliance with CPAP [21]. Again, these findings illustrate the need for data to use in prospective decision-making in the individual patient, including potential combination therapies for OSA, in order to improve the clinical effectiveness of the treatment [22].

Altogether, this collection of papers on DISE illustrates the strong interest in further standardization and exploration of this evolving technique in terms of predicting non-PAP treatment outcome. The results are highly promising for the goal of finding more effective treatment of OSA when being tailored to each patient's need. A personalized medicine approach is highly relevant for this particular patient group, given the complex pathophysiology of OSA, the variable clinical presentation, the relevant comorbidities, and the potential contribution of undiagnosed or untreated SDB to poor outcomes [23]. In the future, DISE will have an expanded role in the clinical evaluation and management of patients with sleepdisordered breathing.

From the editorial board of Sleep and Breathing we do hope that the readership of the journal enjoys reading this collection of recent papers on DISE.

\section{References}

1. Croft CB, Pringle M (1991) Sleep nasendoscopy: a technique of assessment in snoring and obstructive sleep apnoea. Clin Otolaryngol Allied Sci 16:504-509

2. Vanderveken OM (2013) Drug-induced sleep endoscopy (DISE) for non-CPAP treatment selection in patients with sleepdisordered breathing. Sleep Breath 17:13-14

3. Vanderveken OM (2018) The global and evident need to increase the validity and uniformity when performing drug-induced sleep endoscopy. Sleep Breath 22:191-192

4. De Vito A, Carrasco Llatas M, Vanni A, Bosi M, Braghiroli A, Campanini A, de Vries N, Hamans E, Hohenhorst W, Kotecha BT, Maurer J, Montevecchi F, Piccin O, Sorrenti G, Vanderveken OM, Vicini C (2014) European position paper on drug-induced sedation endoscopy (DISE). Sleep Breath 18:453-465

5. De Vito A, Carrasco Llatas M, Ravesloot MJ, Kotecha B, De Vries N, Hamans E, Maurer J, Bosi M, Blumen M, Heiser C, Herzog M, Montevecchi F, Corso RM, Braghiroli A, Gobbi R, Vroegop A, Vonk PE, Hohenhorst W, Piccin O, Sorrenti G, Vanderveken OM, Vicini C. (2018) European position paper on drug-induced sleep endoscopy: 2017 update. Clinical Otolaryngology: Official Journal of ENT-UK; Official Journal of Netherlands Society for Oto- Rhino-Laryngology \& Cervico-Facial Surgery

6. Vonk PE, Beelen A, de Vries N (2018) Towards a prediction model for drug-induced sleep endoscopy as selection tool for oral 
appliance treatment and positional therapy in obstructive sleep apnea. Sleep Breath

7. Beelen AMV, de Vries N (2018) Drug-induced sleep endoscopy: the effect of different passive maneuvers on the distribution of collapse patterns of the upper airway in obstructive sleep apnea patients. Sleep Breath

8. Kim YPH, Shin J, Choi JH, Park SW, Kang HY (2018) Effect of remifentanil during drug-induced sleep endoscopy in patients with obstructive sleep apnea. Sleep Breath

9. Dieltjens M, Vroegop AV, Verbruggen AE, Wouters K, Willemen M, De Backer WA, Verbraecken JA, Van de Heyning PH, Braem MJ, de Vries N, Vanderveken OM (2014) A promising concept of combination therapy for positional obstructive sleep apnea. Sleep Breath

10. Lee JJ, Sahu N, Rogers R, Soose RJ (2015) Severe obstructive sleep apnea treated with combination hypoglossal nerve stimulation and oral appliance therapy. Journal of Dental Sleep Medicine 2:185-186

11. Vanderveken OM, Maurer JT, Hohenhorst W, Hamans E, Lin HS, Vroegop AV, Anders C, de Vries N, Van de Heyning PH (2013) Evaluation of drug-induced sleep endoscopy as a patient selection tool for implanted upper airway stimulation for obstructive sleep apnea. J Clin Sleep Med 9:433-438

12. Koutsourelakis I, Safiruddin F, Ravesloot M, Zakynthinos S, de Vries N (2012) Surgery for obstructive sleep apnea: sleep endoscopy determinants of outcome. Laryngoscope 122:2587-2591

13. Eichler C, Sommer JU, Stuck BA, Hormann K, Maurer JT (2013) Does drug-induced sleep endoscopy change the treatment concept of patients with snoring and obstructive sleep apnea? Sleep Breath 17:63-68

14. Zerpa Zerpa V, Carrasco Llatas M, Agostini Porras G, Dalmau Galofre J (2015) Drug-induced sedation endoscopy versus clinical exploration for the diagnosis of severe upper airway obstruction in OSAHS patients. Sleep Breath 19:1367-1372

15. Wang Y, Sun C, Cui X, Guo Y, Wang Q, Liang H (2018) The role of drug-induced sleep endoscopy: predicting and guiding upper airway surgery for adult OSA patients. Sleep Breath
16. Strollo PJ Jr, Soose RJ, Maurer JT, de Vries N, Cornelius J, Froymovich O, Hanson RD, Padhya TA, Steward DL, Gillespie MB, Woodson BT, Van de Heyning PH, Goetting MG, Vanderveken OM, Feldman N, Knaack L, Strohl KP, Group ST (2014) Upper-airway stimulation for obstructive sleep apnea. New Engl J Med 370:139-149

17. Vanderveken OM, Beyers J, Op de Beeck S, Dieltjens M, Willemen M, Verbraecken JA, De Backer WA, Van de Heyning PH (2017) Development of a clinical pathway and technical aspects of upper airway stimulation therapy for obstructive sleep apnea. Front Neurosci 11:523

18. Hasselbacher K, Seitz A, Abrams N, Wollenberg B, Steffen A (2018) Complete concentric collapse at the soft palate in sleep endoscopy: what change is possible after UPPP in patients with CPAP failure? In: Sleep breath

19. Kastoer C, Benoist LBL, Dieltjens M, Torensma B, de Vries LH, Vonk PE, Ravesloot MJL, de Vries N (2018) Comparison of upper airway collapse patterns and its clinical significance: drug-induced sleep endoscopy in patients without obstructive sleep apnea, positional and non-positional obstructive sleep apnea. Sleep Breath

20. Benoist LBL, Verhagen M, Torensma B, van Maanen JP, de Vries N (2017) Positional therapy in patients with residual positional obstructive sleep apnea after upper airway surgery. Sleep Breath 21:279-288

21. Lan MC, Hsu YB, Lan MY, Huang YC, Kao MC, Huang TT, Chiu TJ, Yang MC (2017) The predictive value of drug-induced sleep endoscopy for CPAP titration in OSA patients. Sleep Breath

22. Vanderveken OM (2015) Combination therapy for obstructive sleep apnea in order to achieve complete disease alleviation: from taboo to new standard of care? Journal of Dental Sleep Medicine 2:7-8

23. Bonsignore MR, Suarez Giron MC, Marrone O, Castrogiovanni A, Montserrat JM (2017) Personalised medicine in sleep respiratory disorders: focus on obstructive sleep apnoea diagnosis and treatment. Eur Respir Rev 26:170069 